\title{
Changes in cause-specific mortality among the elderly in Canada, 1979-2011
}

\author{
Marie-Pier Bergeron-Boucher ${ }^{1}$ \\ Robert Bourbeau \\ Jacques Légaré
}

\begin{abstract}
The structure of causes of death in Canada has been changing since the onset of the "cardiovascular revolution." While mortality due to cardiovascular diseases has been declining, mortality due to other causes of death, such as cancers and Alzheimer's disease has been increasing. Our research investigates how these changes have re-modeled life expectancy at age 65 and age 85 , and what specific causes of death are involved. We distinguish between premature and senescent deaths in Canada, using a cause-specific age structure. Our results suggest that although a decline in premature deaths has contributed to increasing life expectancy in recent years, most of the gains in life expectancy at age 65 and 85 have resulted from a decline in senescent deaths. We also find a decline in mortality due to the main causes of death, leading to a greater diversification of causes.
\end{abstract}

Keywords: Causes of death, life expectancy, age patterns of mortality, Canada, decomposition.

\section{Résumé}

Depuis le début de la révolution cardiovasculaire, le Canada a connu d'importants changements dans la distribution des décès selon la cause. La mortalité par maladies cardiovasculaires a connu une importante diminution alors que les taux de mortalité pour les cancers et pour la maladie d'Alzheimer ont augmenté. Cet article examine comment ces changements ont influencé les tendances de l'espérance de vie à 65 et à 85 ans et quelles causes de décès spécifiques furent impliquées. Une distinction entre les décès prématurés et les décès liés à un processus de sénescence est réalisée, se basant sur deux indicateurs de variations par âge des causes de décès. Nos résultats suggèrent que la majorité des gains en espérance de vie à 65 et 85 ans proviennent d'une plus faible mortalité par cause de décès sénescente. De plus, une diminution des principales causes de décès chez les personnes âgées de 65 ans et plus laisse place à une plus grande diversification de causes aux grands âges.

Mots-clés : Causes de décès, espérance de vie, variations par âge, Canada, décomposition.

\section{Background}

Life expectancy has undergone an important increase over the last 170 years in many industrialized countries (Oeppen and Vaupel 2002). Changes in age and cause of death structures of mortality account for this development. The epidemiological transition, as formulated by Omran (1971), summarizes these changes. The epidemiological transition involves a shift from a high to a low stable level of mortality, in which degenerative and man-made diseases replace infectious diseases as the main causes of death (Omran 1971). It also involves an important transformation of the age structure of mortality, i.e., the average age at death shifts from young ages toward older ages. The epidemiological transition was observed in many industrialized countries until the 1970s

\footnotetext{
1. Marie-Pier Bergeron-Boucher, Max-Planck Odense Center on the Biodemography of Aging, University of Southern Denmark, Department of Epidemiology, Biostatistics and Biodemography, J.B. Winsløws Vej 9, 5000 Odense C, Denmark, email: mpbergeron@health.sdu.dk; co-authors Robert Bourbeau and Jacques Légaré, Department of Demography, Université de Montréal.
} 
(Meslé and Vallin 2000). However, in most of these countries, mortality levels from degenerative and man-made diseases did not stabilize, as suggested by Omran (1971), but a further decline in mortality due to cardiovascular diseases was observed (Meslé and Vallin 2000). These changes in the structure of causes of death have resulted in a further increase in life expectancy for many industrialized countries.

Between 1921 and 2011, life expectancy at birth in Canada increased from 56.0 to 79.5 years for males and from 58.2 to 83.7 for females (CHMD 2015). Progress in life expectancy at birth was initially driven by a reduction in infant mortality. However, since the middle of the twentieth century, most of this increase has resulted from mortality reduction at higher ages (Decady and Greenberg 2014). These changes have enabled life expectancy at birth to keep rising, but have also caused life expectancy at higher ages to increase over time (Vallin and Meslé 2010). For example, between 1950 and 2011, life expectancy at age 65 in Canada increased from 13.3 to 18.9 years for males and from 15.0 to 21.8 for females (CHMD 2015).

Reductions in cause-specific mortality occurring at higher ages, as in the case of cardiovascular diseases, have been the main drivers of life expectancy increase in Canada since the 1950s (Decady and Greenberg 2014). Death rates from heart and cerebrovascular diseases decreased by 37.4 and 39.2 per cent, respectively, between 1981 and 2007 (Milan 2011). However, mortality due to other causes of death rose over the same period. Mortality due to cancers increased until the middle of the 1990s but has since begun to decrease. An increase in mortality due to diabetes and Alzheimer's disease has also been observed (Milan 2011). However, less is known about how these changes have influenced Canadian life expectancy trends, and how the cause of death structure has changed since the cardiovascular revolution.

Decady and Greenberg (2014) state that most of the progress in life expectancy in Canada in the past 90 years has come from a decline in premature deaths. Premature deaths are defined by the authors as deaths occurring among individuals aged less than 75 years. Other indicators of premature deaths are also often used, such as potential years of life lost (PYLL), which also uses a cutoff age (e.g., 70 or 75) under which a person's death will be considered premature (OECD 2016). The concept of premature deaths refers to deaths occurring at younger ages, which are before their time and could, a priori, have been preventable. Premature deaths are often contrasted with senescent deaths, which tend to result from a more natural aging process and to occur at older ages (Brody and Schneider 1986; Horiuchi 2007). Senescent mortality here refers to the increase over age in the risk of dying, resulting from gradual physical deterioration with age (Bongaarts 2005; Vaupel 2010).

Instead of defining premature deaths as deaths occurring before a fixed age, some authors have preferred to look at the age structure of cause-specific mortality (Brody and Schneider 1986; Horiuchi 2007; Horiuchi and Wilmoth 1997). Causes of death have their own specific age structure: some tend to occur during childhood, others around middle age, and some at older ages. The age structure of causes of death reveals information about physiological and biological changes with age, but also about individual differences in longevity (Horiuchi 2007). Age-variation analyses of causes of death have also been useful in understanding how diseases develop: some diseases have been shown to develop prematurely and selectively among certain individuals, whereas others appear at old or very old ages and may reflect a senescence process (Brody and Schneider 1986; Horiuchi 2007).

Our research aims to analyze changes in causes of death at age 65 and older in Canada since 1979 via three objectives. We first look at changes in life expectancy trends at ages 65 and 85 years. Given these changes in life expectancy trends, we determine different historical time periods and calculate, for each of these periods, the age- and cause-specific contribution to life expectancy increase, in order to evaluate emergent and declining causes of death and their impact on general mortality. Finally, we establish age variation patterns of causes of death, to distinguish between premature and senescent causes of death in Canada.

\section{Data}

Data on causes of death are taken from the Canadian Vital Statistics from 1979 to 1999, provided by Statistics Canada, which publishes causes of death data after collating and grouping information from the provinces and territories where data are collected. Causes of death data from 2000 to 2011 were extracted from CANSIM tables published by Statistics Canada (Statistics Canada 2015a, 2015b, 2015c, 2015d, 2015e, 2015f, 2015g). The 
data are available for 5 -year age groups, with the last available age-group being 90 years and older $(90+)$. The data on population and exposure to risk were extracted from the Canadian Human Mortality Database (CHMD), which provides historical data based on population surveys and censuses in Canada (CHMD 2015).

Deaths are classified according to the International Classification of Diseases (ICD), which has changed over the years. In the period from 1979 to 2011, the ICD was changed only once in Canada, in 2000, from ICD9 (WHO 1977) to ICD-10 (WHO 2010). However, this change was one of the most major that the ICD has undergone, leading to important discontinuities in some causes of death time-series, e.g., those for pneumonia and Alzheimer's disease (Geran et al. 2005; Meslé and Vallin 2008). To avoid such discontinuities, data on causes of death before 1999 and after 2000 are analyzed as two different series.

The ten main causes of death at age 65 and older in Canada are selected (Table 1). In 2011, these causes represented 75.7 per cent of all deaths at age 65 and older. Neoplasms are divided into five subgroups of causes: cancers of the lung, bronchitis and trachea (LBT), colon and rectum (CR), breast, prostate, and other cancers.

Table 1. ICD-9 and ICD-10 codes for the selected causes of death and their proportions (\%) at age 65 years and older in 1979, 1995, and 2011, Canada

\begin{tabular}{|c|c|c|c|c|c|}
\hline Causes of death & ICD-9 & ICD-10 & $\% 1979$ & $\% 1995$ & $\% 2011$ \\
\hline 1 Malignant neoplasms & $140-208$ & $\mathrm{C} 00-\mathrm{C} 97$ & 21.4 & 25.4 & 27.8 \\
\hline Lung, bronchitis, and trachea cancer & 162 & C33-C34 & 4.4 & 6.5 & 7.4 \\
\hline Colon and rectum cancer & $153-154$ & $\mathrm{C} 18-\mathrm{C} 21$ & 3.2 & 2.9 & 3.3 \\
\hline Breast cancer & $174-175$ & $\mathrm{C} 50$ & 1.4 & 1.8 & 1.6 \\
\hline Prostate cancer & 185 & C61 & 1.7 & 2.2 & 1.8 \\
\hline Other cancers & $\begin{array}{l}140-152 \\
155-161 \\
163-173 \\
176-184 \\
186-208\end{array}$ & $\begin{array}{l}\mathrm{C} 00-\mathrm{C} 17 ; \\
\mathrm{C} 22-\mathrm{C} 32 ; \\
\mathrm{C} 35-\mathrm{C} 49 ; \\
\text { C51-C60; } \\
\text { C62-C97 }\end{array}$ & 10.7 & 12.0 & 13.7 \\
\hline 2 Heart diseases & $\begin{array}{l}390-398 \\
402 ; 404 \\
410-429\end{array}$ & $\begin{array}{l}\text { I00-I09; } \\
\text { I11; I13; } \\
\text { I20-I51 }\end{array}$ & 40.2 & 30.6 & 21.3 \\
\hline 3 Cerebrovascular diseases & $430-438$ & I60-I69 & 11.8 & 8.8 & 6.3 \\
\hline 4 Chronic lower respiratory diseases & 490-94; 496 & $\mathrm{~J} 40-\mathrm{J} 47$ & 3.4 & 5.2 & 5.4 \\
\hline 5 Diabetes mellitus & 250 & E10-E14 & 2.0 & 2.8 & 3.1 \\
\hline 6 Alzheimer's disease & 331.0 & G30 & 0.0 & 1.7 & 3.3 \\
\hline 7 Influenza and pneumonia & $480-487$ & J10-J18 & 3.3 & 4.3 & 2.7 \\
\hline 8 Accidents & $\begin{array}{l}\text { E800-E869; } \\
\text { E880-E929 }\end{array}$ & $\begin{array}{l}\text { V01-X59; } \\
\text { Y85-Y86 }\end{array}$ & 2.4 & 2.1 & 3.2 \\
\hline $\begin{array}{l}9 \text { Nephritis, nephrotic syndrome } \\
\text { and nephropathy }\end{array}$ & $580-589$ & $\begin{array}{c}\text { N00-N07; } \\
\text { N17-N19; } \\
\text { N25-27 }\end{array}$ & 1.0 & 1.4 & 1.6 \\
\hline 10 Parkinson's diseases & 332 & G20-G21 & 0.3 & 0.7 & 1.0 \\
\hline 11 Other diseases & - & - & 14.2 & 17.0 & 24.3 \\
\hline
\end{tabular}

Sources: Canadian Vital Statistics 1979-99, Statistics Canada (2015a, 2015b, 2015c, 2015d, 2015e, 2015f, 2015g), and Geran et al. (2005).

\section{Methods}

\section{Changes in life expectancy at ages 65 and 85 years: Segmented regression}

To evaluate changes in life expectancy trends, a segmented regression methodology is used. The segmented regression method was introduced by Muggeo (2003) and applied in the life expectancy context by Camarda et al. (2012). This method aims to find the slopes and breakpoints of a piecewise linear regression, formed of two or more linear segments connected at unknown values (Camarda et al. 2012). Ouellette et al. (2014) also used this method to find discontinuities in general, and in age-and cause-specific mortality trends. When there is only one breakpoint, the method corresponds to:

$$
e_{x}(t)=\alpha_{x}+\beta_{x}^{1} t+\beta^{2}{ }_{x}\left(t-\psi_{x}\right)^{+},
$$


where $e_{x}(t)$ is the life expectancy at age $x$ and year $t, \beta^{l}{ }_{x}$ is the slope of the first segment, $\beta^{2}{ }_{x}$ is the difference between the slope of the first and the second segment, and $\psi_{x}$ is the breakpoint. Then, $\left(t-\psi_{x}\right)^{+}=\left(t-\psi_{x}\right) *$ $I\left(t>\psi_{x}\right)$, where $I$ is an indicator function equal to 1 when the year $t$ is higher than the breakpoint year $\left(t>\psi_{x}\right)$ (Camarda et al. 2012).

\section{Contribution to changes in life expectancies}

Evaluation of age and cause of death contributions to changes in life expectancy is done using standard decomposition methods (Arriaga 1984; Preston et al. 2001). The contributions are calculated for different periods, based on the breakpoints resulting from the segmented regression.

\section{Age variation}

The age profile of each cause of death is based on two indicators. The first is the proportion between age $x$ and $x+n$ of cause $i,{ }_{n} p_{x}^{i}(t)$, calculated as

$$
{ }_{n} p_{x}^{i}(t)={ }_{n} D_{x}^{i}(t) /{ }_{n} D_{x}(t)
$$

where ${ }_{n} D_{x}(t)$ and ${ }_{n} D_{x}^{i}(t)$ are the total and cause $i$ number of observed deaths between ages $x$ and $x+n$ for year $t$, respectively. This indicator shows the relative importance of causes of death at specific ages (Horiuchi 2007).

The second indicator is the life table aging rate (LAR). The LAR is interpreted as the slope of an exponential curve. Constant LARs through ages thus represent an exponential increase with age of the death rates (Horiuchi and Wilmoth 1997). This indicator allows us to see whether and how the increase of the death rates for a specific cause is accelerating or decelerating with age. The LAR for a cause of death $i$ at age $x$ is estimated as

$$
L A R_{x}^{i}(t)=\left[\ln \left({ }_{n} M_{x}^{i}(t)\right)-\ln \left({ }_{n} M_{x-n}^{i}(t)\right)\right] / n,
$$

where ${ }_{n} M_{x}^{i}(t)$ is the death rate of cause $i$ between ages $x$ and $x+n$ for year $t$.

These indicators thus represent two different aspects of causes of death age variation: the proportions show the relative importance of causes of death at each age and the LARs show if the risk of dying from a specific cause of death accelerates or decelerates with age, and whether it increases (positive LARs) or decreases (negative LARs). Both indicators are compared to validate each other's results.

\section{Results}

\section{Breakpoints in life expectancy at ages 65 and 85 years}

Life expectancy at age 65 and 85 years $\left(e_{65}\right.$ and $\left.e_{85}\right)$ has undergone a major increase in Canada over the twentieth century. However, Figure 1 shows that this progress has not been linear and a number of different breaks in the trends can be observed. Three breakpoints in life expectancy at age 65 years for females were detected since 1921 (1943, 1987, and 1998), but only two for males (1972 and 1998). For trends in life expectancy at age 85, there were three breakpoints for each sex: 1949, 1989, and 1998 for females and 1947, 1984, and 1999 for males.

Before the first breakpoint, in the mid-1940s, progress in life expectancy at age 65 and 85 years was modest. Based on the maximum life expectancy observed each year, Vallin and Meslé (2010) determined that the increase in life expectancy after the first breakpoint was the result of the cardiovascular revolution. Reductions in cardiovascular mortality enabled life expectancy at higher ages to increase. In Canada, these progresses only became evident on $e_{65}$ after 1972 for males.

In the middle of the $1980 \mathrm{~s}$, the rate of increase in $e_{65}$ for females and $e_{85}$ for both sexes decelerated. For the first time, life expectancy for males began to increase faster than for females. Since 1998-99, life expectancies for both sexes and at both ages have increased at a faster pace than in any other observed period. In the next section, we present the age and cause contributions to these changes in life expectancy. 


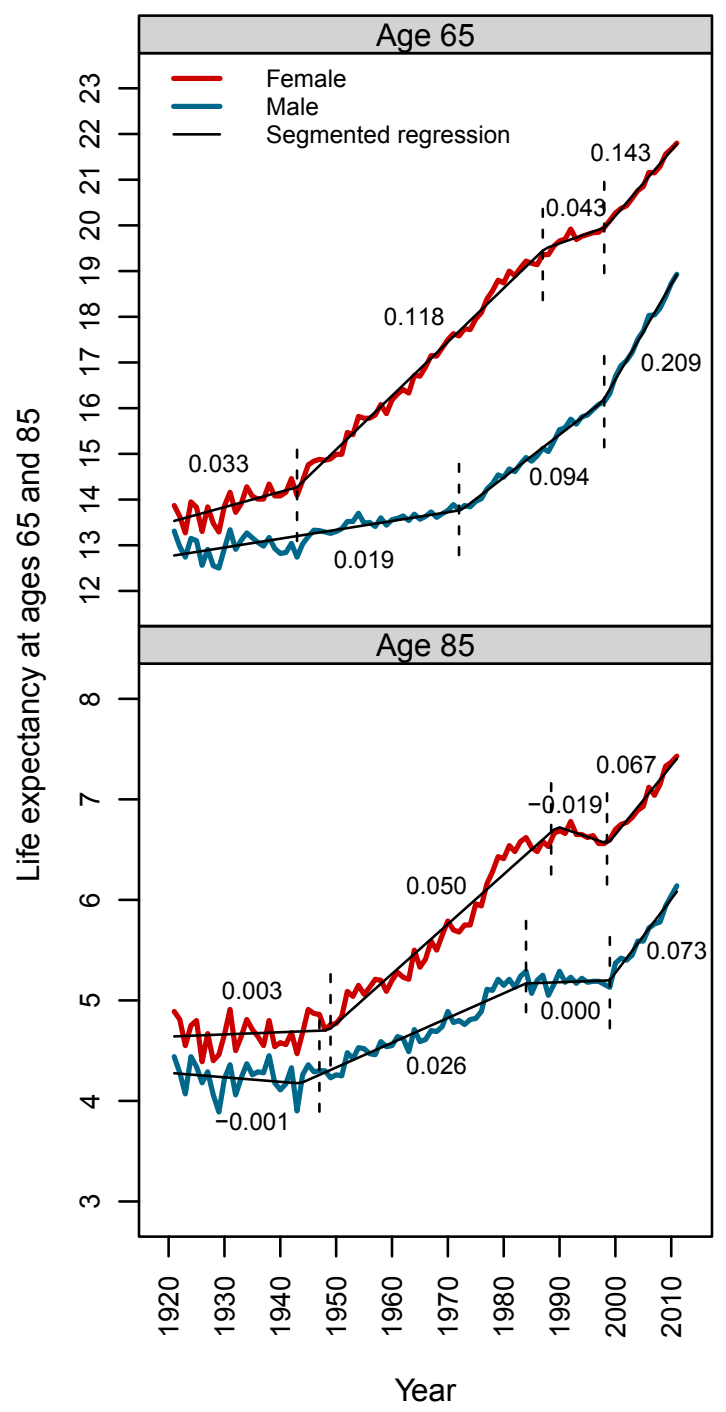

Figure 1. Canadian life expectancy at ages 65 and 85 years by sex, associated segmented regressions, and respective slopes, 1921-2011.

Sources: CHMD (2015) and authors' own calculations.

\section{Age and cause of death contributions to changes in life expectancy}

Based on the breakpoints identified in the previous section and the causes of death data constraints, we determined three historical periods of change: 1979-85, 1985-99, and 2000-11. In these three periods, life expectancy at age 65 increased, respectively, by $0.32,0.88$, and 1.59 years for females and by $0.29,1.46$, and 2.31 years for males.

\section{Age contributions}

Figure 2 shows the annualized age- and cause-specific contribution to changes in $e_{65}$. For the period 197985, 88 per cent (for males) and 51 per cent (for females) of the changes in life expectancy at age 65 were the result of lower mortality between ages 65 and 74 years. A large part of the increase in life expectancy therefore came about because of a decline in premature mortality, as defined by Decady and Greenberg (2014). However, these proportions decreased to 44 and 31 per cent, respectively, in 2000-11. Changes taking place at older ages are thus playing a greater role in the increase in life expectancy in recent years. 


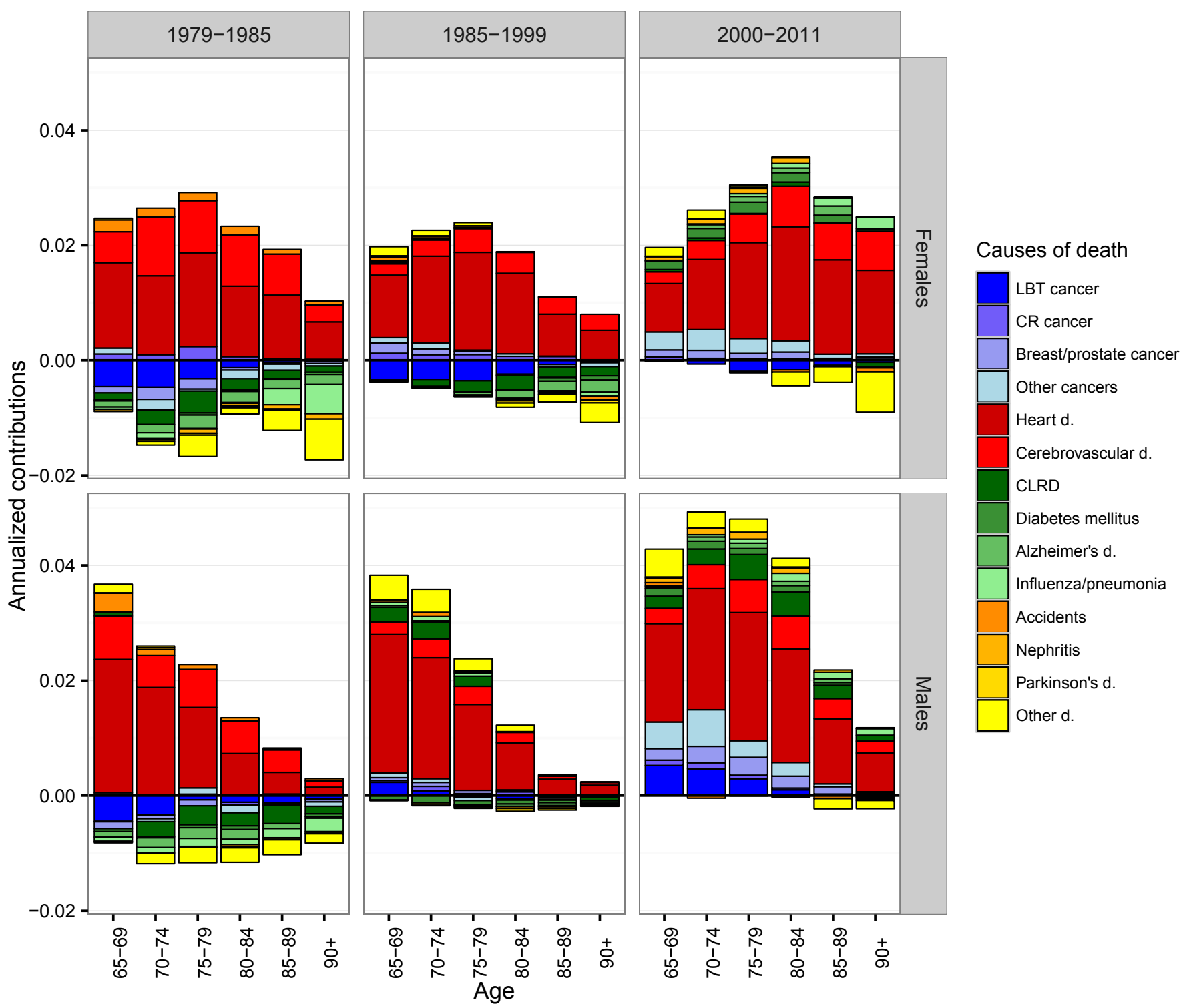

Figure 2. Annualized age and causes of death contribution to the increase in Canadian life expectancy at age 65 by sex, period 1979-85, 1985-99, and 2000-11.

Sources: Canadian Vital Statistics 1979-99, Statistics Canada (2015a, 2015b, 2015c, 2015d, 2015e, 2015f, 2015g), CHMD (2015), and authors' own calculations.

\section{Cause contributions}

Regardless of the period, the increase in life expectancy at age 65 is mainly the result of a decrease in mortality due to cardiovascular diseases (CVD), which include heart and cerebrovascular diseases (Figure 2). For the period 1979-85, most of the other selected causes contributed to reduce $e_{65}$, especially cancers, chronic lower respiratory diseases, Alzheimer's disease, and influenza and pneumonia.

Over the period 1985-99, the main causes of death were now contributing positively, or made only very small negative contributions, to the $e_{65}$ increase for males. However, the increase in life expectancy for females continued to be slowed down by lung, bronchitis, and trachea (LBT) cancer, chronic lower respiratory diseases (CLRD), Alzheimer's disease, and the residual group of causes. Females experienced a loss of 0.43 years in life expectancy due to these last four causes, while males gained 0.27 years as a result of changes in those same causes (see Appendix A). These differences explain why female $e_{65}$ increased less than that of males during this period, together with a greater contribution from heart diseases for males. Smaller gains in cerebrovascular diseases were also observed for both sexes over this same period. 
In the period 2000-11, $e_{65}$ for both sexes increased at a faster pace than in the previous periods. Most causes of death were now showing positive or null gains in terms of life expectancy, with the exception of LBT cancer for females, and accidents and "other causes" at older ages for both sexes. Appendix B shows that the death rates at 65 years and older by cause of death, with exception of the three previously mentioned causes, have been decreasing or stayed approximately constant since 2000 .

Given the increasing importance of older age-groups in life expectancy changes, we also looked at the cause-specific contributions to changes in $e_{85}$. Appendix A shows similar results for the decomposition of life expectancy at age 85 and age 65 years. The deceleration in the $e_{85}$ trend observed between 1985 and 1999 (Figure 1) is partially explained by a lower annualized gain in terms of cerebrovascular diseases compared to the previous period, and by a negative contribution for most of the other causes.

\section{Age variation profile of causes of death}

As suggested by Horiuchi (2007), we use the age of 85 years to separate "younger-old age" from "oldest-old age" mortality, when looking at the proportions by age. We distinguish between causes of death that are more prevalent before (downward trends) or after (upward trends) age 85 (see Figures C1 and C2 in Appendix C).

The age variation of causes of death using LARs shows that the increase in some cause-specific death rates decelerates (decreasing LARs) with age, while it accelerates (increasing LARs) for other causes (see Figures C3 and C4 in Appendix C). The LARs even become negative after a certain age for some causes, meaning that the death rates are decreasing with age. Based on this indicator, we separate cause of death LARs that decrease with age from those which stay constant or increase (see Appendix D for more details on the classification criteria).

Table 2. Causes of death classified according to their age variation using proportions and life table aging rates (LARs), Canada, 1979-2011

\begin{tabular}{lll}
\hline & $\begin{array}{l}\text { Lower proportions before age 85 } \\
\text { (Upward trends) }\end{array}$ & $\begin{array}{l}\text { Higher proportions before age 85 } \\
\text { (Downward trends) }\end{array}$ \\
\hline Decreasing LAR & $\begin{array}{l}\text { Cerebrovascular diseases (Male) } \\
\text { Alzheimer's disease }\end{array}$ & $\begin{array}{l}\text { Lung, bronchitis and trachea cancer } \\
\text { Colon and rectum cancer (Male) } \\
\text { Prostate cancer } \\
\text { Other cancers }\end{array}$ \\
& & $\begin{array}{l}\text { Chronic lower respiratory diseases } \\
\text { Diabetes mellitus }\end{array}$ \\
Constant or increasing LAR & Parkinson's disease \\
& $\begin{array}{l}\text { Heart diseases } \\
\text { Cerebrovascular diseases (Female) and rectum cancer (Female) } \\
\text { Influenza and pneumonia }\end{array}$ & Breast cancer \\
Accidents & \\
Nephritis, nephrotic syndrome and & \\
nephropathy & \\
Other diseases & \\
\hline
\end{tabular}

According to these definitions, two main patterns of causes can be distinguished, as shown in Table 2 . The first pattern shows higher proportions before age 85 years and decreasing LARs over age. These causes have a higher relative importance at youngest-old ages than at oldest-old ages, and the risk of dying from these causes decelerates or decreases with age. The decrease in the proportions and LARs with age could come from (1) a tendency of these causes to develop early in life; and/or (2) other causes of death tending to take over mortality at higher ages. This pattern is consistent with Horiuchi's (2007) findings for the US White population, where this category represents causes of death that tend to develop prematurely and selectively among certain individuals. They are also often associated with certain risk factors, such as smoking, diet, heredity, etc.

The second pattern shows higher proportions after age 85 years, and increasing or constant LARs over age. These causes have a higher relative importance at the oldest-old ages, and the risk of dying from them increases and often accelerates with age. Causes included in this group thus occur at older ages, and tend to be more associated with a process of senescence. As Horiuchi and Wilmoth (1997) also pointed out, competing risk among 
causes of death is more important after a certain age, so that as a result of senescence, people become more susceptible to death from causes that develop more rapidly than from other causes which take longer to result in death. An example for males is given in Figure 3 for LBT cancer and for accidents, representing the two age patterns, respectively (see Appendix $C$ for the other causes).

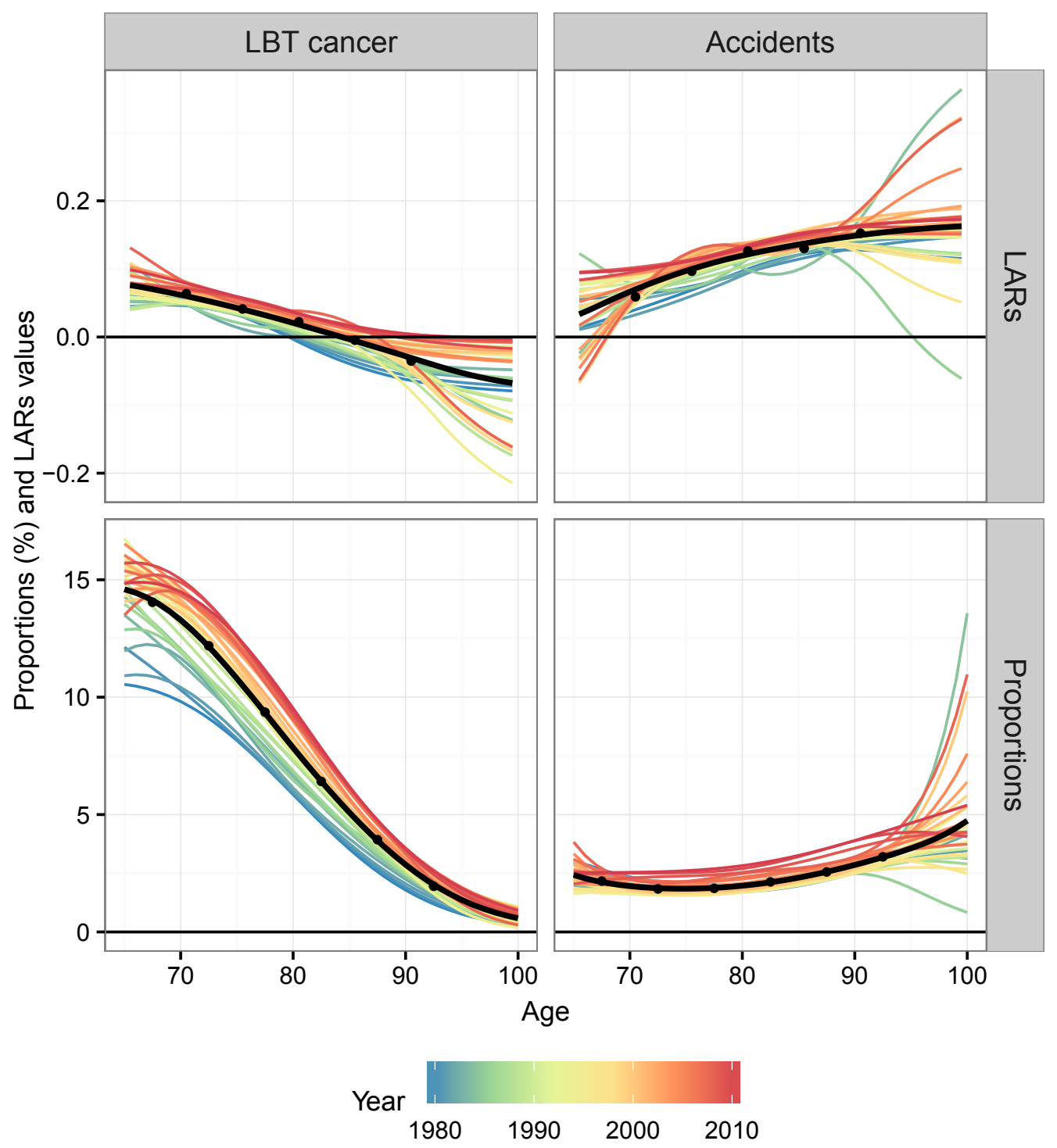

Figure 3. Age variation for Lung, bronchial, and trachea cancer and Accidents using proportions and life table aging rates (LARs), observed (dot) and smoothed (line), Males, Canada, 1979-2011 and age-specific average over time (in black).

Note: The trends are smoothed using a P-spline smoothing procedure for Poisson death counts (Camarda 2012).

Sources: Canadian Vital Statistics 1979-99, Statistics Canada (2015a, 2015b, 2015c, 2015d, 2015e, 2015f, 2015g), CHMD (2015), and authors'own calculations.

There are, however, some exceptions to these two patterns. Alzheimer's and cerebrovascular diseases (male) have more importance at higher ages, although their LARs decrease with age. Breast cancer and CR cancer (female) have more importance at younger ages; however, their LARs do not decrease with age. These results may be due to inadequate classification criteria or specification of the cause of death, but more research would be needed to explain them fully.

Using the classification of deaths discussed earlier, in 1979 premature deaths represented about 21 and 30 per cent of total deaths at age 65 years and older for females and males, respectively, compared with 31 and 
Bergeron-Boucher, Bourbeau, and Légaré: Cause-specific mortality among the elderly

41 per cent in 2011, including CR cancer deaths as premature deaths for females. This change in proportions may be a result of the decline in deaths due to cardiovascular diseases, classified as senescent, and the increase in cancer deaths observed up to the beginning of the 21st century. Between 1979 and 1985, premature deaths contributed to a loss of 0.17 years of life expectancy at age 65 for females and 0.18 years for males. However, between 2000 and 2011 they contributed to increasing $e_{65}$ by 0.20 and 0.75 years for females and males, respectively, representing 13 and 32 per cent of the total increase in that period.

These results point to some particular characteristics of the Canadian population and of the health conditions in Canada. The main drivers of the loss of premature years in life expectancy at age 65 years in the period 1979-85 were increases in mortality from lung, bronchitis, and trachea cancers and from chronic lower respiratory diseases (Appendix A). These two last causes of death are highly influenced by tobacco consumption (CDC 2016). A decline in smoking among the Canadian population could have enabled more of these deaths to be prevented in more recent years, especially for males (CCSSC 2010).

However, changes in premature deaths have not been the main drivers of mortality changes since 1979. Gains in life expectancy at age 65 years have mainly resulted from a decrease in senescent deaths, including heart diseases. Vaupel (2010) has argued that although senescence is inevitable for human populations, it can nonetheless be postponed, and this has been made possible by ongoing improvements in health care. It has led to declines in senescence-associated causes of death, with the result that mortality decrease is observed at higher and higher ages.

\section{Discussion}

In Canada, deaths classified as premature (first age pattern) represented about 26 per cent of all deaths at age 65 and older in 1979 and about 36 per cent in 2011, for both sexes combined. Most of these deaths are considered to be less senescence-related, and so to be untimely and potentially preventable. An increase in premature deaths might reflect a greater burden of certain risk factors, e.g., smoking (lung, bronchitis and trachea cancer, and chronic lower respiratory diseases) and diet (diabetes). This information is potentially useful for prevention and treatment programs. And in fact, a reduction in tobacco consumption in Canada has resulted in decreased mortality due to cancer of the lung, trachea, and bronchitis and to chronic lower respiratory diseases among males. Female mortality due to these causes has, however, increased since 1979, because of a time lag in female patterns of tobacco consumption relative to males (CCSSC 2010).

But the main influence on changes in life expectancies at age 65 and 85 years since 1979 has been a decrease in senescent deaths. As one important explanatory variable for these causes is age, the increasing number of people reaching higher ages should have enhanced mortality pressure due to causes that occur at very advanced ages. However, it has been possible to successfully reduce death rates for these diseases, as shown by the major decline in mortality from cardiovascular diseases. Still, even if the senescence process can be postponed (Vaupel 2010), it cannot be avoided, and all individuals eventually become vulnerable to multiple diseases (Horiuchi 2007). The decrease in the main causes of death and the increase in age at death might lead toward a greater diversification of causes of death at old ages.

The decrease in mortality from the main causes of death, with no apparent mortality increase in other specific-causes since 2000 (Appendix B), except for LBT cancer for females and accidents for both sexes, is likely to lead to a greater diversification of causes of death. Mortality due to predominant causes is decreasing, whereas the other causes of death are tending to increase in relative importance-without, however, becoming predominant causes (Table 1). This diversification is also reflected in an increase in mortality and proportions for the residual group of causes. Causes included in this group are very diverse, and none of them accounted for more than 2 per cent of the deaths in 2011. Increases in life expectancy and advancing age come with an increasing vulnerability to multiple diseases, reflecting a "long-term accumulation of unrepaired damages, leading to simultaneous deterioration of many physiological functions" (Horiuchi 2007: 231). The decrease in mortality due to the main causes of death, together with the increase in life expectancy, means that a diversification of causes of death at old ages is likely to take place. 
The use of age 85 as a threshold between youngest-old and oldest-old ages may be questionable. For example, Kannisto (1994) defined the oldest-old as people aged 80 years and higher. Using this threshold instead would not have changed much our results, with the exception of Parkinson's disease. The 80- and 85-year thresholds are often used, but do not reflect the dynamic process of aging itself (Tomassini 2005). Other, more dynamic indicators, such as modal age at death, might be more appropriate.

Another potential limitation to this study is that the selected period of 1979-85 may not be the most relevant in terms of comparing a previous period with the deceleration in $e_{65}$ and $e_{85}$ of 1985-99, because the period is short and may already embody some features of the cause of death changes of the subsequent period.

It is also important to note that there are underlying problems with cause of death data, which may bias the results ((Désesquelles and Meslé 2004; Geran et al. 2005; Meslé and Vallin 2008). After a certain age, competing risks between different causes of death grow, as the chances of dying from various diseases increase. This may lead to misreporting on death certificates. Some causes of death seem to be more often declared as the primary cause of death, while other causes will be considered as secondary causes (Désesquelles and Meslé 2004). This is the case with diabetes, for example. Diabetes seems to contribute frequently to the morbid process among the elderly, but is rarely stated as the primary cause of death (Désesquelles and Meslé 2004).

The impact of the ICD changes is also not well understood, and may have led to greater discontinuities than expected (Geran et al. 2005). As shown in Appendix B, there are important discontinuities in the time trends of influenza and pneumonia. The drastic decrease in the death rates of influenza and pneumonia is related to an important change in the rule to classify pneumonia: in ICD-10, pneumonia is now accepted as a complication of any disease (WHO 2010). Pneumonia is thus considered more often as a secondary cause of death than a primary one with the ICD-10 than with the ICD-9. This has led to an important decrease in the number of deaths due to pneumonia and to a corresponding increase in the related primary conditions (Geran et al. 2005; Meslé and Vallin 2008).

Another underlying problem with the causes of death series is changes in the perception and knowledge of a disease. As an example, Alzheimer's disease was considered as a rare disease until the end of the 1970s, but a better understanding of the disease and its delineation from dementia increased the number of diagnoses and deaths classified as Alzheimer's since (Boller and Forbes 1998). Progress in perception and knowledge of this disease is still ongoing. An increase in the death rates of Alzheimer's disease from ICD-9 to ICD-10 is observed as dementia in and due to Alzheimer, classify as Senile and pre-senile organic psychotic conditions in ICD-9, are classify to Alzheimer's disease in ICD-10 (Geran et al. 2005; Meslé and Vallin 2008).

Although we study causes of death trends classified with ICD-9 and ICD-10 as two different series in this article, these discontinuities in the trends and changes in disease knowledge could affect the results. However, despite these limitations, cause of death data still inform us regarding changes in cause of death structure in Canada.

\section{Conclusion}

Changes in the cause of death structure are ongoing in Canada, and the main causes of death among people aged 65 years and older have been decreasing in importance since 2000. A decrease in premature deaths is observed, but the main gains in life expectancy at age 65 and 85 years come from a decline in senescence-related causes of death. These changes have led to a major increase in life expectancy at age 65 and 85 years. Furthermore, as a result of the decline in the main causes of death and the corresponding increase in life expectancy, a greater diversification of causes of death may take place at older ages.

\section{Acknowledgments}

This paper is based on results from Marie-Pier Bergeron-Boucher's Master's thesis research, carried out under the supervision of Robert Bourbeau and Jacques Légaré, of the Department of Demography at the Université de Montréal. The authors are grateful to Vladimir Canudas-Romo, of the Max-Planck Odense Center on the Biodemography of Aging, for his useful comments. 


\section{References}

Arriaga, E.E. 1984. Measuring and explaining the change in life expectancies. Demography 21(1):83-96.

Boller, F., and M.M. Forbes. 1998. History of dementia and dementia in history: An overview. Journal of Neurological Sciences 158:125-33.

Bongaarts, J. 2005. Long-range trends in adult mortality: Models and projection methods. Demography 42(1):23-49.

Brody, J.A., and E.L. Schneider. 1986. Diseases and disorders of aging: An hypothesis. Journal of Chronic Diseases 39(11):871-76.

Camarda, G., J. Vallin, and F. Meslé. 2012. Identifying the Ruptures Shaping the Segmented Line of Secular Trends in Maximum Life Expectancies. Paper presented at the 2012 European Population Conference: Gender, Policies, and Population, Stockholm, Sweden (June 13-16).

Camarda, G. 2012. MortalitySmooth: An R package for smoothing Poisson counts with P-splines. Journal of Statistical Software 50(1):1-24.

CCSSC (Canadian Cancer Society's Steering Committee). 2010. Canadian Cancer Statistics 2010. Toronto: Canadian Cancer Society.

CDC (Centers for Disease Control and Prevention). 2016. Health Effects of Cigarette Smoking [Fact sheet]. Retrieved from https://www.cdc.gov/tobacco/data_statistics/fact_sheets/health_effects/effects_cig_ smoking/

CHMD. 2015. Canadian Human Mortality Database. Department of Demography, University of Montreal (Canada). Available at www.demo.umontreal.ca/chmd/(data downloaded on March 2015).

Decady, Y., and L. Greenberg. 2014. Ninety years of change in life expectancy. Health at a Glance Report (Cat. no. 82-624-X). Ottawa: Statistics Canada.

Désesquelles, A., and F. Meslé. 2004. Intérêt de l'analyse des causes multiples dans l'étude de la mortalité aux grands âges : l'exemple francais. Cabier québécois de démographie 33(1):83-116.

Geran, L., P. Tully, P. Wood, and B. Thomas. 2005. Comparability of ICD-10 and ICD-9 for Mortality Statistics in Canada. Health Statistics Division Report (Cat. No. 84-548-XIE). Ottawa: Statistics Canada.

Horiuchi, S. 2007. Causes of death among the oldest-old: Age-related changes in the cause-of-death distribution, in J.-M. Robine, E. Crimmins, S. Horiuchi, and Z. Yi (eds.), Human Longevity, Individual Life Duration, and the Growth of the Oldest-Old Population. International Studies in Population 4. Netherlands: Springer, p. 215-35.

Horiuchi, S., and J.R. Wilmoth .1997. Age patterns of the life table aging rate for major causes of death in Japan, 1951-1990. The Journals of Gerontology Series A: Biological Sciences and Medical Sciences 52A(1): B67-B77.

Kannisto, V. 1994. Development of Oldest-Old Mortality, 1950-1990: Evidence from 28 Developed Countries. Monographs on Population Aging 1. Odense (Denmark): Odense University Press.

Meslé, F., and J. Vallin. 2000. Transition sanitaire : tendances et perspectives. Médecine/Science 16(11):1161-71.

Meslé, F., and J. Vallin. 2008. The effect of ICD-10 on continuity in cause-of-death statistics: The example of France. Population (English edn) 63(2):347-59.

Milan, A. 2011. Mortality: Causes of Death, 2007. Report on the Demographic Situation in Canada (Component of Cat. No. 91-209-X). Ottawa: Statistics Canada.

Muggeo, V.M.R. 2003. Estimating regression models with unknown break-points. Statistics in Medicine 22(19):3055-71.

OECD. 2016. Potential Years of Life Lost (Indicator). doi: 10.1787/193a2829-en (Accessed on 2 December 2016)

Oeppen, J., and J.W. Vaupel. 2002. Broken limits to life expectancy. Science 296(5570):1029-31. 
Omran, A.R. 1971. The epidemiologic transition: A theory of the epidemiology of population change. The Milbank Memorial Fund Quarterly 49(4):509-38.

Ouellette, N., M. Barbieri, and J.R. Wilmoth. 2014. Period-based mortality change: Turning points in trends since 1950. Population and Development Review 40(1):77-106.

Preston, S., P. Heuveline, and M. Guillot. 2001. Demography: Measuring and Modeling Population Processes. Oxford: Blackwell Publishing.

Statistics Canada. 2015a. Table 102-0522 - Deaths, by cause, Chapter II: Neoplasms (C00 to D48), age group and sex, Canada, annual (number), 2000 to 2011, CANSIM (database).

Statistics Canada. 2015b. Table 102-0524 - Deaths, by cause, Chapter IV: Endocrine, nutritional and metabolic diseases (E00-E90), age group and sex, Canada, annual (number), 2000 to 2011, CANSIM (database).

Statistics Canada. 2015c. Table 102-0526 - Deaths, by cause, Chapter VI: Diseases of the nervous system (G00-G99), age group and sex, Canada, annual (number), 2000 to 2011, CANSIM (database).

Statistics Canada. 2015d. Table 102-0529 - Deaths, by cause, Chapter IX: Diseases of the circulatory system (I00 to I99), age group and sex, Canada, annual (number), 2000 to 2011, CANSIM (database).

Statistics Canada. 2015e. Table 102-0530 - Deaths, by cause, Chapter X: Diseases of the respiratory system (J00 to J99), age group and sex, Canada, annual (number), 2000 to 2011, CANSIM (database).

Statistics Canada. 2015f. Table 102-0534 - Deaths, by cause, Chapter XIV: Diseases of the genitourinary system (N00-N99), age group and sex, Canada, annual (number), 2000 to 2011, CANSIM (database).

Statistics Canada. 2015g. Table 102-0540 - Deaths, by cause, Chapter XX: External causes of morbidity and mortality (V01-Y89), age group and sex, Canada, annual (number), 2000 to 2011, CANSIM (database).

Tomassini, C. 2005. The demographic characteristics of the oldest old in the United Kingdom. Population Trends 120:15-22.

Vallin, J., and F. Meslé. 2010. Will life expectancy increase indefinitely by three months every year? Population and Societies 473:1-4.

Vaupel, J.W. 2010. Biodemography of human ageing. Nature 464:536-42.

WHO (World Health Organization). 1977. Manual of the International Statistical Classification of Diseases, Injuries and Causes of Death. Ninth rev edn, vol. 1. Geneva: World Health Organization.

-2010. ICD-10. International Statistical Classification of Diseases and Related Health Problems. Tenth rev edn, vol. 2. Geneva: World Health Organization. 


\section{Appendix A. Cause of death contributions to change in life expectancy at age 65 and 85 years}

Table A1. Cause of death contributions to the increase in Canadian life expectancy at ages 65 and 85 years, by sex, for the periods 1979-85, 1985-99, and 2000-11

\begin{tabular}{|c|c|c|c|c|c|c|c|c|c|c|c|c|}
\hline \multirow{3}{*}{ Causes of death } & \multicolumn{6}{|c|}{$\mathrm{e}_{65}$} & \multicolumn{6}{|c|}{$\mathrm{e}_{85}$} \\
\hline & \multicolumn{3}{|c|}{ Males } & \multicolumn{3}{|c|}{ Females } & \multicolumn{3}{|c|}{ Males } & \multicolumn{3}{|c|}{ Females } \\
\hline & $\begin{array}{r}1979 \\
-1985 \\
\end{array}$ & $\begin{array}{r}1985 \\
-1999 \\
\end{array}$ & $\begin{array}{r}2000 \\
-2011 \\
\end{array}$ & $\begin{array}{r}1979 \\
-1985 \\
\end{array}$ & $\begin{array}{r}1985 \\
-1999 \\
\end{array}$ & $\begin{array}{r}2000 \\
-2011 \\
\end{array}$ & $\begin{array}{r}1979 \\
-1985 \\
\end{array}$ & $\begin{array}{r}1985 \\
-1999 \\
\end{array}$ & $\begin{array}{r}2000 \\
-2011 \\
\end{array}$ & $\begin{array}{r}1979 \\
-1985 \\
\end{array}$ & $\begin{array}{r}1985 \\
-1999 \\
\end{array}$ & $\begin{array}{r}2000 \\
-2011 \\
\end{array}$ \\
\hline Total & 0.29 & 1.46 & 2.31 & 0.32 & 0.88 & 1.59 & -0.16 & 0.08 & 0.87 & 0.00 & 0.03 & 0.81 \\
\hline $\begin{array}{l}\text { Lung, bronchi, and } \\
\text { trachea cancer }\end{array}$ & -0.07 & 0.03 & 0.15 & -0.09 & -0.19 & -0.06 & -0.04 & -0.01 & 0.00 & -0.01 & -0.03 & -0.03 \\
\hline Colon and rectum cancer & 0.00 & 0.03 & 0.03 & 0.03 & 0.06 & 0.02 & -0.01 & 0.01 & 0.00 & 0.00 & 0.02 & 0.00 \\
\hline Breast cancer & - & - & - & -0.04 & 0.04 & 0.06 & - & - & - & -0.01 & 0.00 & 0.01 \\
\hline Prostate cancer & -0.02 & 0.02 & 0.13 & - & - & - & -0.01 & -0.02 & 0.05 & - & - & - \\
\hline Other cancers & 0.00 & 0.01 & 0.19 & -0.02 & 0.02 & 0.14 & -0.01 & -0.02 & 0.02 & -0.02 & -0.03 & 0.03 \\
\hline Heart diseases & 0.41 & 1.02 & 1.08 & 0.45 & 0.97 & 0.97 & 0.12 & 0.22 & 0.54 & 0.22 & 0.35 & 0.62 \\
\hline Cerebrovascular diseases & 0.18 & 0.16 & 0.26 & 0.26 & 0.26 & 0.34 & 0.11 & 0.05 & 0.17 & 0.13 & 0.16 & 0.26 \\
\hline $\begin{array}{l}\text { Chronic lower respiratory } \\
\text { diseases }\end{array}$ & -0.07 & 0.09 & 0.18 & -0.07 & -0.13 & 0.01 & -0.10 & -0.03 & 0.10 & -0.03 & -0.10 & -0.01 \\
\hline Diabetes mellitus & -0.01 & -0.06 & 0.06 & -0.01 & -0.01 & 0.09 & -0.01 & -0.03 & 0.01 & -0.01 & -0.04 & 0.03 \\
\hline Alzheimer's disease & -0.04 & -0.01 & 0.03 & -0.06 & -0.08 & 0.04 & -0.03 & -0.04 & 0.01 & -0.04 & -0.11 & 0.03 \\
\hline Influenza and pneumonia & -0.05 & 0.02 & 0.05 & -0.06 & -0.01 & 0.05 & -0.09 & 0.00 & 0.07 & -0.10 & -0.02 & 0.07 \\
\hline Accidents & 0.04 & 0.02 & -0.01 & 0.05 & 0.01 & -0.02 & 0.01 & -0.02 & -0.02 & 0.02 & -0.02 & -0.02 \\
\hline $\begin{array}{l}\text { Nephritis, nephrotic } \\
\text { syndrome, and nephrosis }\end{array}$ & 0.00 & -0.02 & 0.05 & -0.02 & -0.01 & 0.04 & -0.01 & -0.01 & 0.01 & -0.02 & -0.01 & 0.00 \\
\hline Parkinson's disease & 0.00 & -0.02 & 0.00 & -0.01 & -0.02 & 0.01 & -0.01 & -0.02 & 0.00 & 0.00 & -0.02 & 0.00 \\
\hline Other diseases & -0.06 & 0.16 & 0.09 & -0.09 & -0.03 & -0.09 & -0.09 & 0.01 & -0.10 & -0.13 & -0.13 & -0.19 \\
\hline
\end{tabular}

Sources: Canadian Vital Statistics 1979-99, Statistics Canada (2015a, 2015b, 2015c, 2015d, 2015e, 2015f, 2015g), CHMD (2015), and authors' own calculations. 


\section{Appendix B. Changes over time of death rates by cause of death}
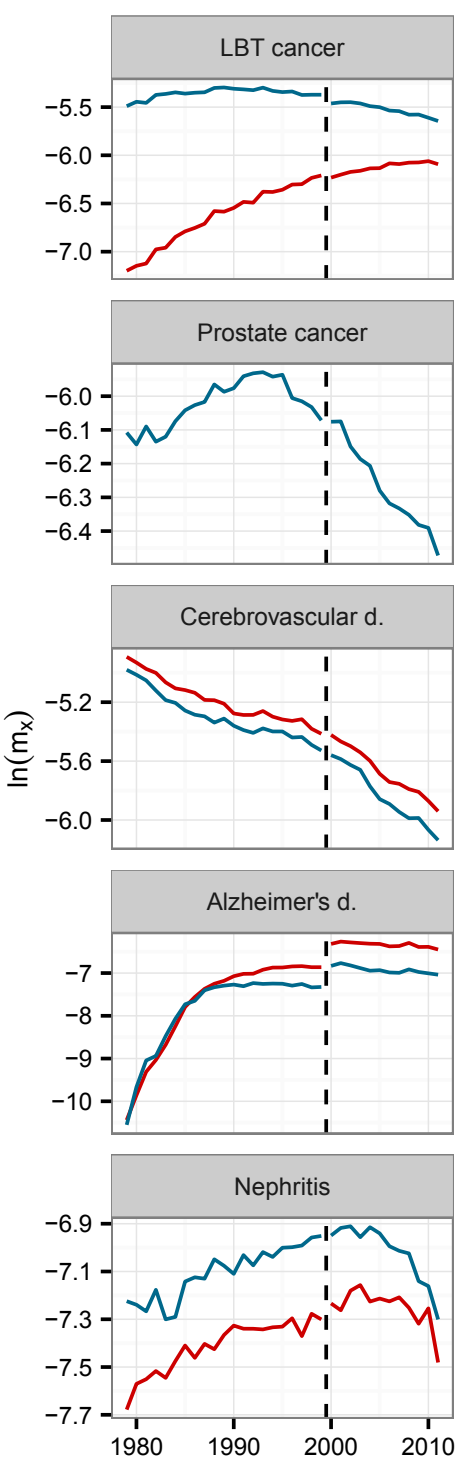
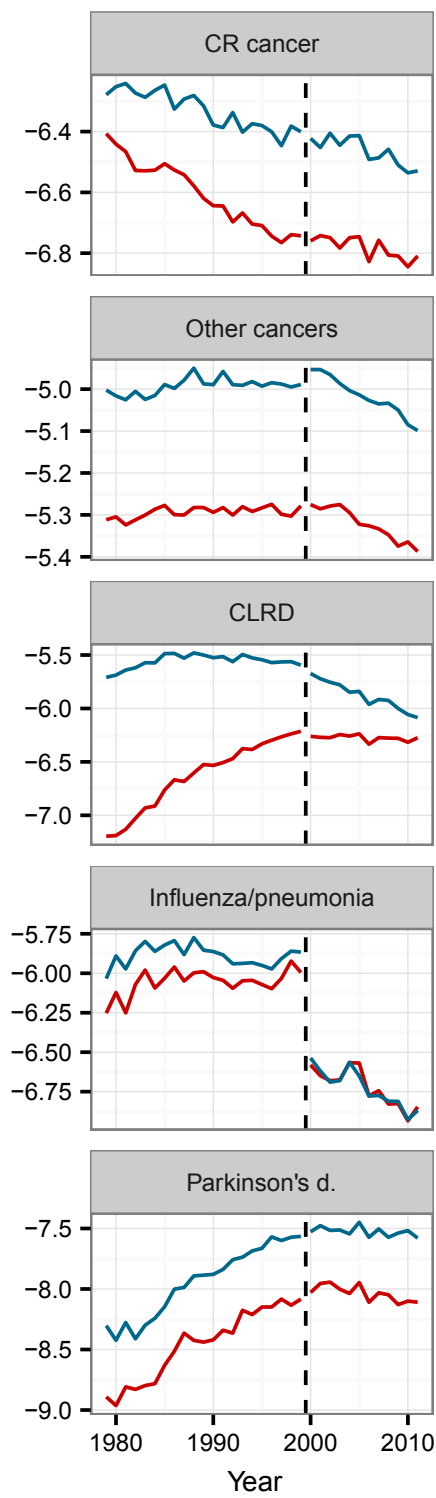
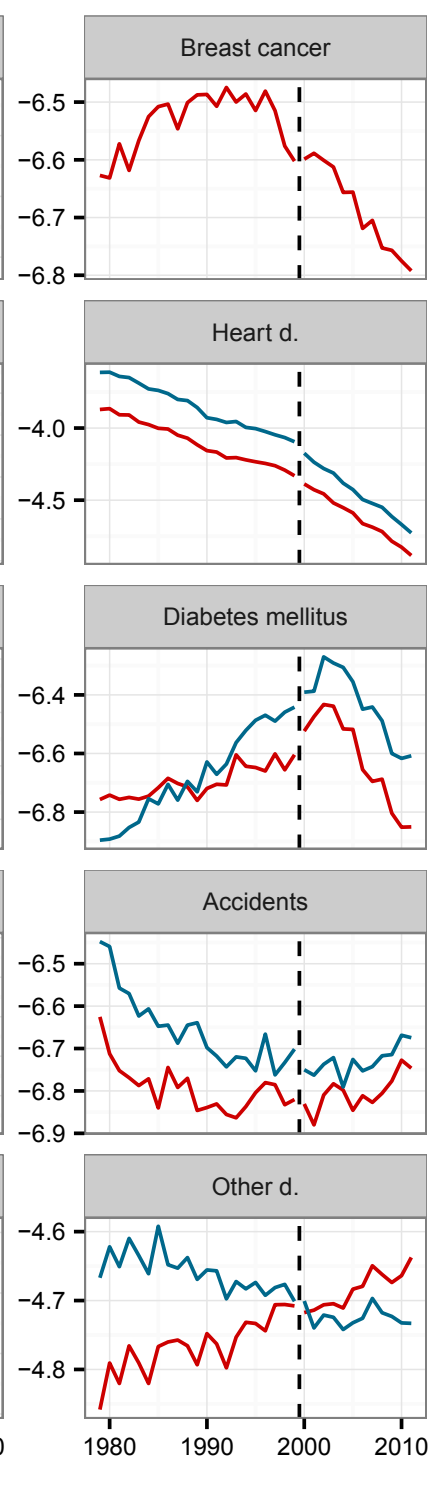

Figure B1. Age-standardized death rates for ages 65 years and older by cause and sex, 1979-2011, Canada.

Note: y-scales might differ from one graph to another to better visualize the time-trends; the standard population is the year 2000.

Sources: Canadian Vital Statistics 1979-99, Statistics Canada (2015a, 2015b, 2015c, 2015d, 2015e, 2015f, 2015g), CHMD (2015), and authors' own calculations. 


\section{Appendix C. Cause-specific age variation: proportions and life table aging rates (LARs)}
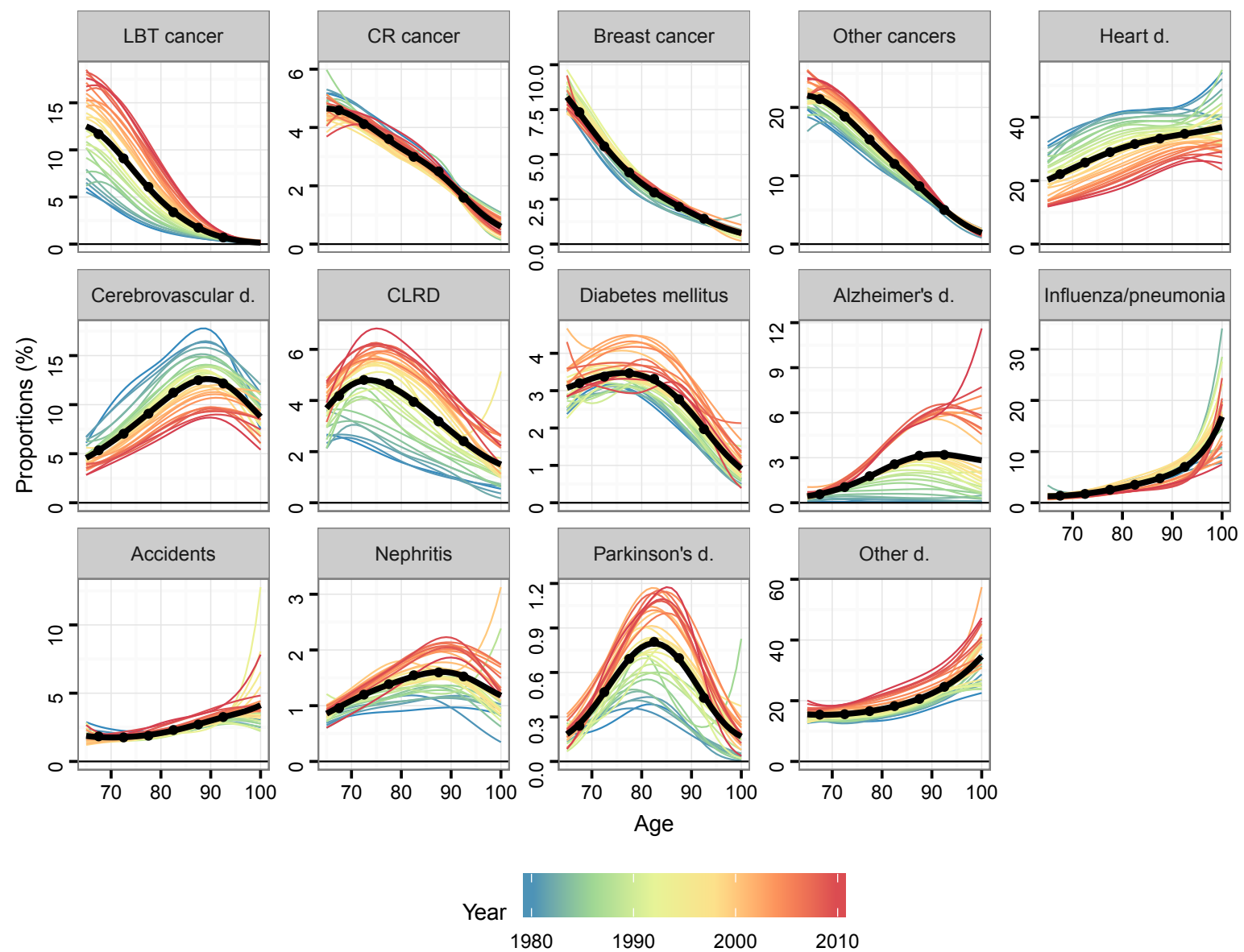

Figure C1. Age variation by cause of death using proportions (expressed in \%) over the period 1979-2011 and age-specific average over time (in black), observed (dot) and smoothed (line), Females, Canada.

Note: $y$-scale might differ from one graph to another to better visualize the age pattern; the trends are smoothed using a P-spline smoothing procedure for Poisson death counts (Camarda 2012).

Sources: Canadian Vital Statistics 1979-99, Statistics Canada (2015a, 2015b, 2015c, 2015d, 2015e, 2015f, 2015g),

CHMD (2015), and authors' own calculations. 

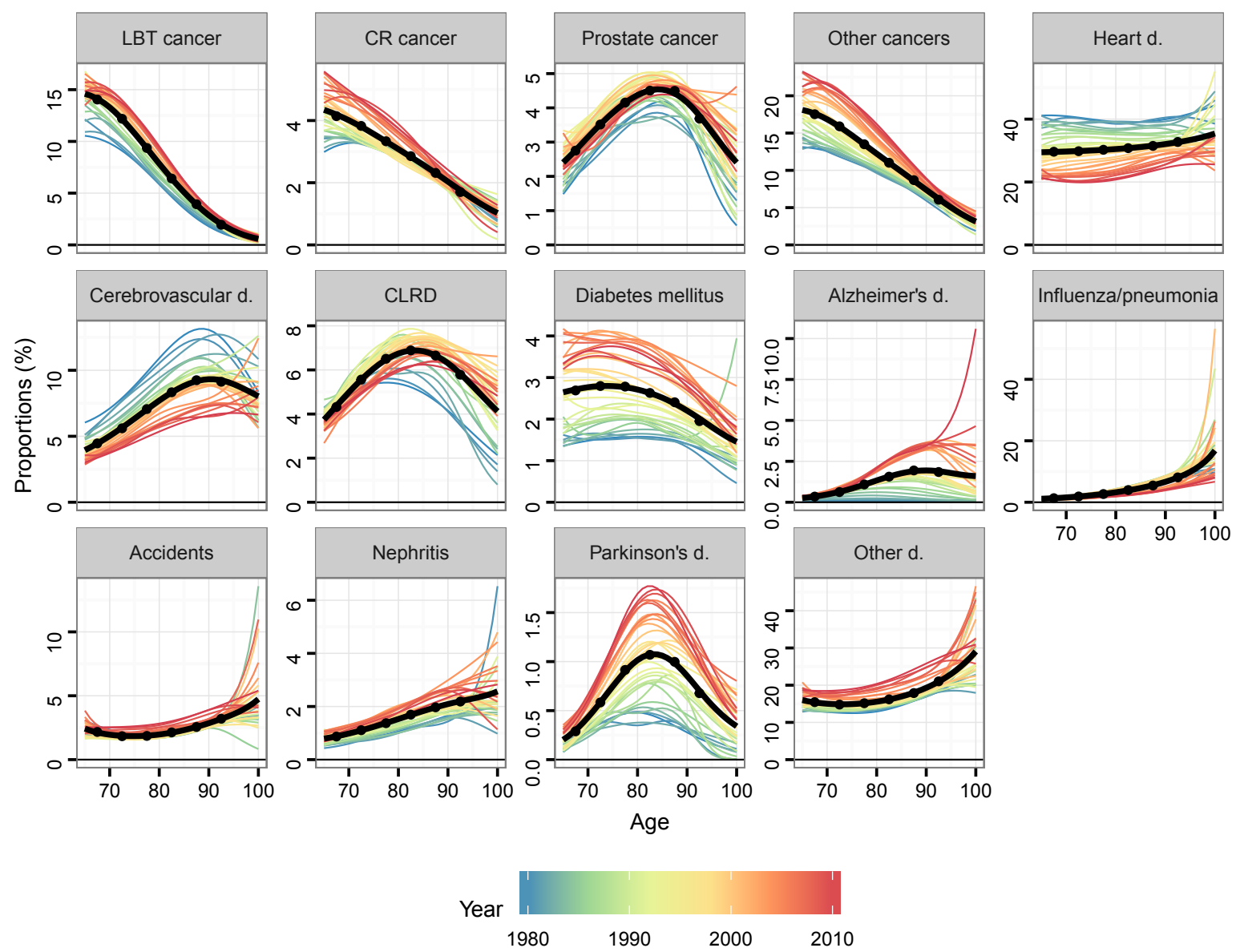

Figure C2. Age variation by cause of death using proportions (expressed in \%) over the period 1979-2011 and age-specific average over time (in black), observed (dot) and smoothed (line), Males, Canada.

Note: y-scale might differ from one graph to another to better visualize the age pattern; the trends are smoothed using a P-spline smoothing procedure for Poisson death counts (Camarda 2012).

Sources: Canadian Vital Statistics 1979-99, Statistics Canada (2015a, 2015b, 2015c, 2015d, 2015e, 2015f, 2015g),

CHMD (2015) and authors' own calculations. 

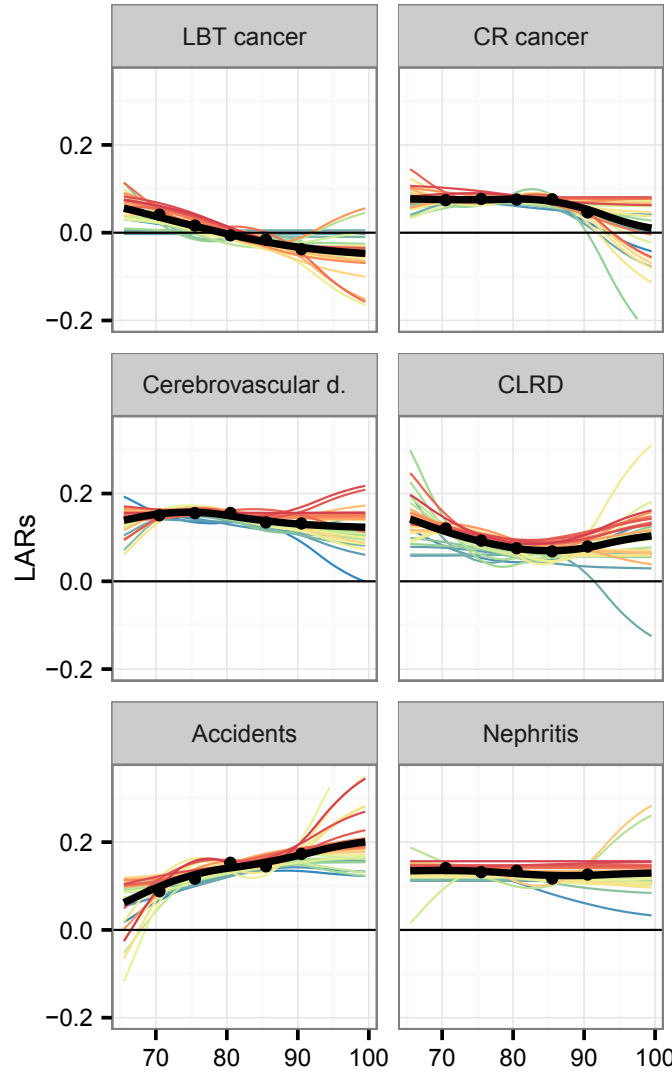
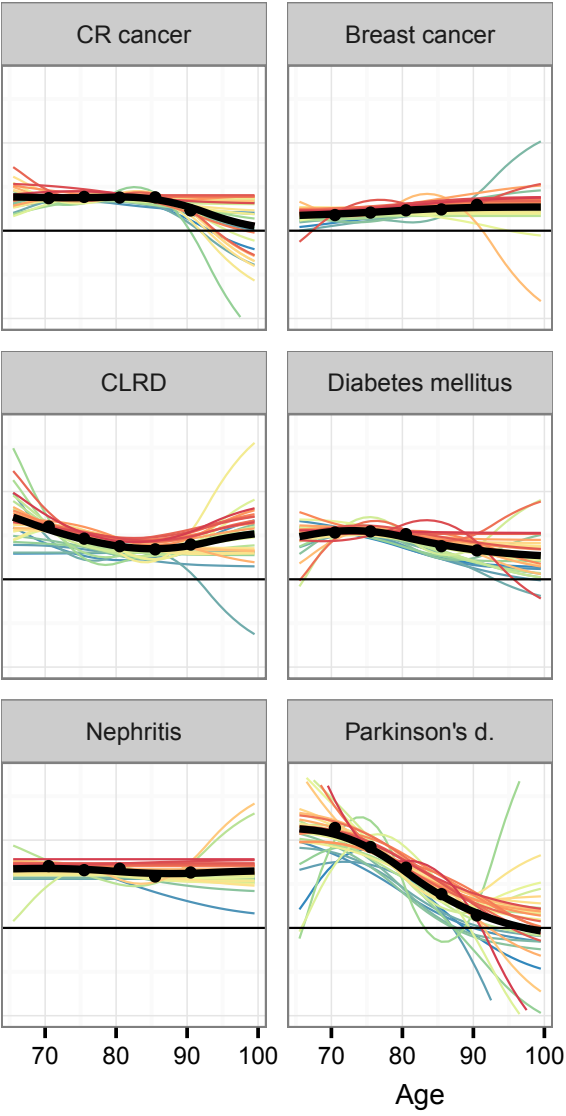
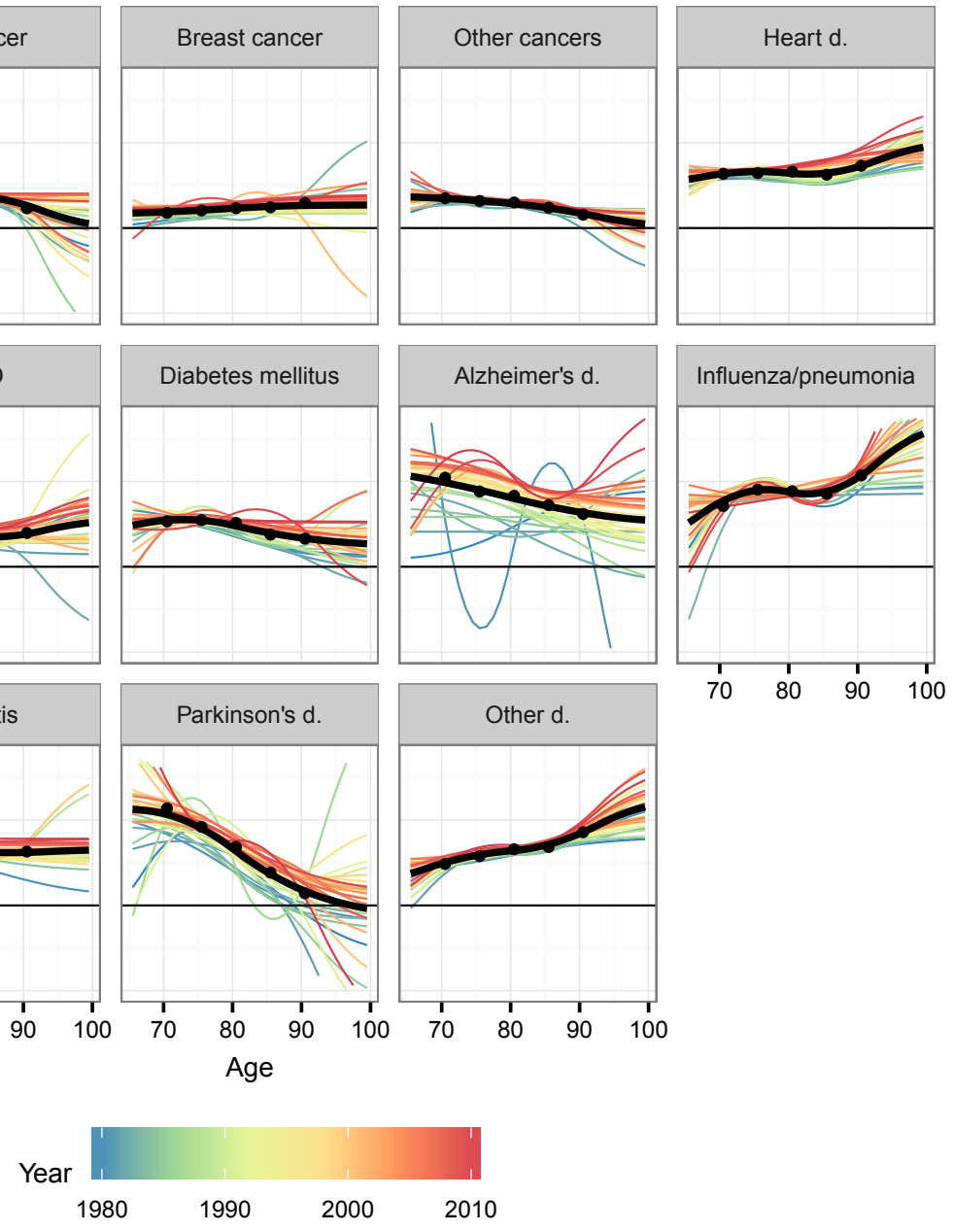

Figure C3. Life table aging rates (LARs) by cause of death over the period 1979-2011 and agespecific average over time (in black), observed (dot) and smoothed (line), Females, Canada.

Note: The trends are smoothed using a P-spline smoothing procedure for Poisson death counts (Camarda 2012).

Sources: Canadian Vital Statistics 1979-99, Statistics Canada (2015a, 2015b, 2015c, 2015d, 2015e, 2015f, 2015g), CHMD (2015) and authors' own calculations. 


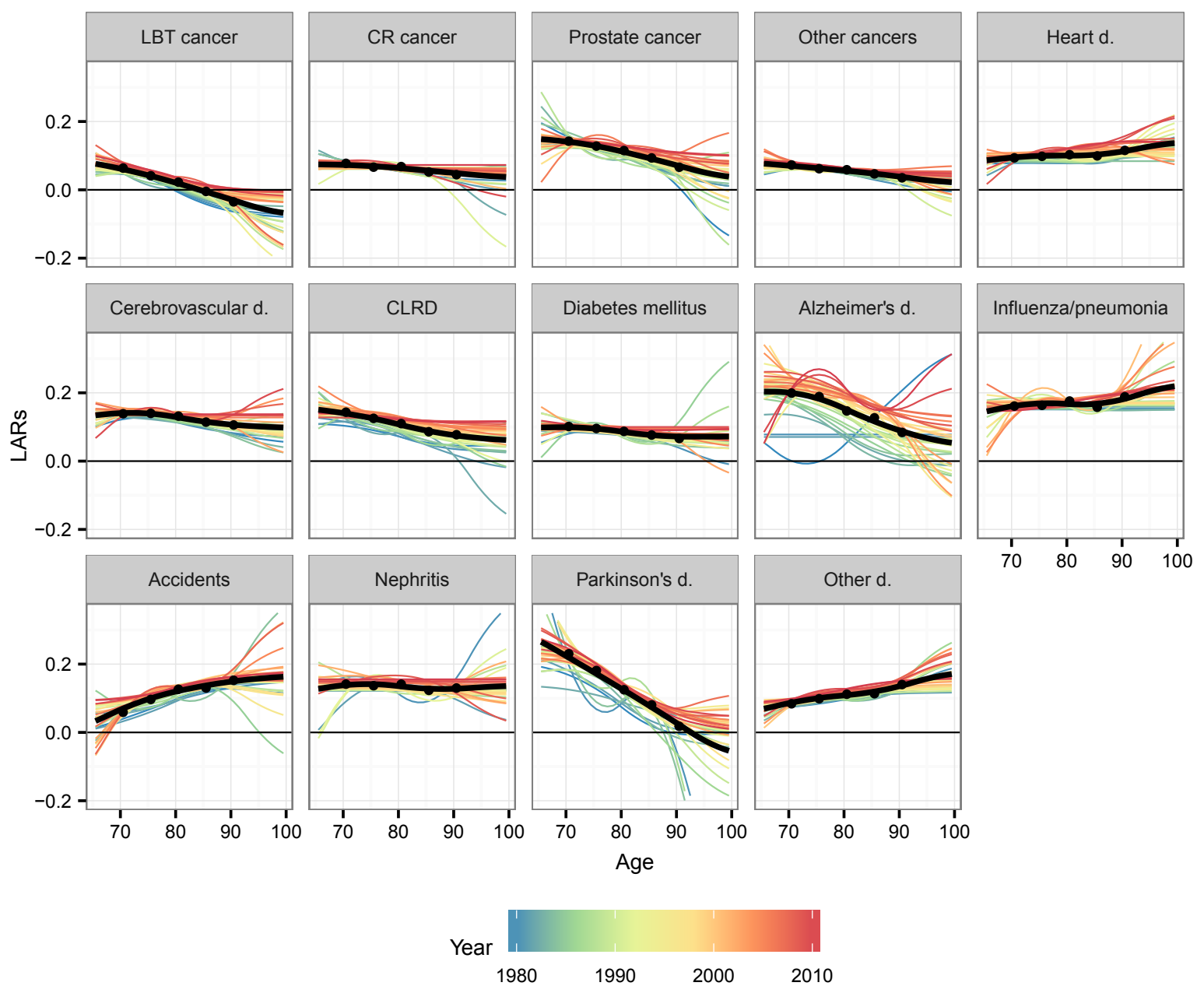

Figure C4. Life table aging rates (LARs) by cause of death over the period 1979-2011 and agespecific average over time (in black), observed (dot) and smoothed (line), Males, Canada.

Note: The trends are smoothed using a P-spline smoothing procedure for Poisson death counts (Camarda 2012). Sources: Canadian Vital Statistics 1979-99, Statistics Canada (2015a, 2015b, 2015c, 2015d, 2015e, 2015f, 2015g), CHMD (2015), and authors' own calculations. 


\section{Appendix D. Causes of death classification criteria}

In the section "Age variation profile of causes of death," we classify the different causes of death based on two age profile indicators: proportions and LARs. For data availability reasons, we only have 6 age groups for our analysis. To help visualize the age pattern, a P-spline smoothing procedure for Poisson death counts is applied to our data, using the Camarda (2012) MortalitySmooth R Package. The data are interpolated and extrapolated for 1 -year age groups for ages from 65 to 100 years.

When looking at the proportions by age we used age 85 to separate younger-old age from oldest-old age mortality. We aim to see if causes of death are more prevalent before or after age 85 . For some causes, as LBT cancer, the visualization of the age pattern could be enough to classify the cause, i.e., if the trends are downward, the proportions are higher at younger-old age, and if the trends are upward, the proportions are higher at oldest-old age. However, the age pattern is sometimes bell-shaped, as in the case of Parkinson's disease. In order to classify the causes between more or less prevalent before age 85 years, we use a ratio of the proportion of death for the 80-84-year age group to the proportion of death for the 85-89-year age group. If the ratio is higher than 1 , the peak of the bell-shaped distribution will occur before age 85 .

To determine if the LARs are decreasing, increasing, or staying constant over age ranges, we applied a linear regression to the LARs, for the non-smoothed trends. A negative or positive slope parameter indicates if the trend is decreasing or increasing. The significance level of the slope parameter ( $\mathrm{p}$-value) indicates if the decrease or increase is significant. If the p-value is higher than 10 per cent, the LARs are considered to be constant over age.

Table D1. Classification criteria for causes of death according to their age variation using proportions and life table aging rates, Canada, average for the period 1979-2011

\begin{tabular}{lcccc}
\hline & \multicolumn{2}{c}{ Proportions } & \multicolumn{2}{c}{ LARs } \\
\cline { 2 - 5 } & $\begin{array}{c}\text { Proportion of } \\
\text { age group 80-84 / } \\
\text { Proportion of } \\
\text { age group } 85-89\end{array}$ & $\begin{array}{c}\text { Direction and } \\
\text { p-value of the } \\
\text { slope parameter of } \\
\text { a linear regression }\end{array}$ \\
\cline { 2 - 5 } Cause of death & Female & Male & Female & Male \\
\hline Lung, bronchitis and trachea cancer & 1.94 & 1.63 & $\mathrm{~N}^{* * *}$ & $\mathrm{~N}^{* * *}$ \\
Colon and rectum cancer & 1.20 & 1.23 & $\mathrm{~N}$ & $\mathrm{~N} * *$ \\
Breast cancer & 1.38 & - & $\mathrm{P}^{* *}$ & - \\
Prostate cancer & - & 1.01 & - & $\mathrm{N} * *$ \\
Other cancers & 1.38 & 1.27 & $\mathrm{~N} * *$ & $\mathrm{~N} * *$ \\
Heart diseases & 0.95 & 0.98 & $\mathrm{P}$ & $\mathrm{P}$ \\
Cerebrovascular diseases & 0.90 & 0.90 & $\mathrm{~N}$ & $\mathrm{~N} *$ \\
Chronic lower respiratory diseases & 1.24 & 1.04 & $\mathrm{~N}$ & $\mathrm{~N} * * *$ \\
Diabetes mellitus & 1.20 & 1.09 & $\mathrm{~N} *$ & $\mathrm{~N} * * *$ \\
Alzheimer's disease & 0.82 & 0.80 & $\mathrm{~N} * *$ & $\mathrm{~N} * *$ \\
Influenza and pneumonia & 0.74 & 0.73 & $\mathrm{P}$ & $\mathrm{P}$ \\
Accidents & 0.85 & 0.83 & $\mathrm{P} *$ & $\mathrm{P}^{* *}$ \\
Nephritis, nephrotic syndrome & 0.97 & 0.86 & $\mathrm{~N}$ & $\mathrm{~N}$ \\
and nephropathy & & & & \\
Parkinson's disease & 1.16 & 1.07 & $\mathrm{~N} * * *$ & $\mathrm{~N} * * *$ \\
Other diseases & 0.88 & 0.91 & $\mathrm{P} * *$ & $\mathrm{P} * *$ \\
\hline
\end{tabular}

Note: Notation for slope parameter direction: N: negative, P: positive. Notation for slope parameter significance level: $* * * p<0.001 ; * * p<0.01 ; * p<0.05 ; p<0.1$ Sources: Canadian Vital Statistics 1979-99, Statistics Canada (2015a, 2015b, 2015c, 2015d, 2015e, 2015f, 2015g), CHMD (2015), and authors' own calculations. 